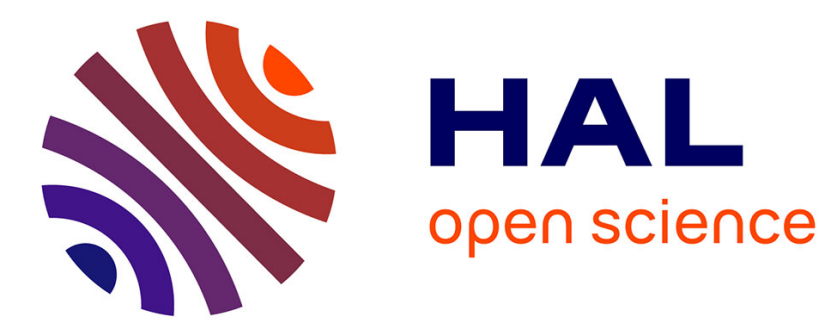

\title{
Understanding dynamic situations through context explanation.
}

\author{
Romain Bénard, Pierre de Loor, Jacques Tisseau
}

\section{To cite this version:}

Romain Bénard, Pierre de Loor, Jacques Tisseau. Understanding dynamic situations through context explanation.. ICALT, 2006, France. pp.1044-1046. hal-00611072

\section{HAL Id: hal-00611072 \\ https://hal.science/hal-00611072}

Submitted on 25 Jul 2011

HAL is a multi-disciplinary open access archive for the deposit and dissemination of scientific research documents, whether they are published or not. The documents may come from teaching and research institutions in France or abroad, or from public or private research centers.
L'archive ouverte pluridisciplinaire HAL, est destinée au dépôt et à la diffusion de documents scientifiques de niveau recherche, publiés ou non, émanant des établissements d'enseignement et de recherche français ou étrangers, des laboratoires publics ou privés. 


\title{
UNDERSTANDING DYNAMIC SITUATIONS THROUGH CONTEXT EXPLANATION
}

\author{
Romain Bénard, Pierre De Loor and Jacques Tisseau \\ CERV European Center for Virtual Reality \\ 25, rue Claude Chappe \\ BP 38 F-29280 Plouzané (France) \\ email :\{benard,deloor,tisseau\}@enib.fr
}

\begin{abstract}
This article presents advantages of using context to set up a pedagogical assistance for recognition of collectives situations in Virtual Environment for Training (VET). We are focusing on generation of explanations to the learner. Two assistances types have been envisaged thanks to context using, the first one consists in guiding the learner before action and the second can be used during action. Those assistances have been set up thanks to contextual graph and consists of animations in the virtual environment.
\end{abstract}

\section{KEY WORDS}

context, explanation, contextual graph, simulation, contextual help

\section{Introduction}

This article deals with the interest of using contextual graphs to set up pedagogical tool in a VET dedicated to dynamic and collaborative situation (DCS) learning. For the learner, the aim is to manage this type of situations. It can be guided thanks to typical intervention such as the highlighting of relevant elements to enhance awareness of a particular concept. In order to do that, some pedagogical techniques such as enrichment, degradation, simplification or the heightening of simulations are used [1].

In the case of a dynamic and collaborative situations, relevant elements extraction is complex because of their dependency to context which is dynamic. That is the reason why we decide to show here the interest of using contextual graph to represent strategical and historical context for explanations.

This article is structured as follows, it begins with a definition of the constructivism learning of dynamic and collaborative situations and help types that can be set up in order to recognize them. The section 3 illustrates the interest of using contextual graphs to make up a visual explanation. An example is given before the conclusion of this article.

\section{Constructivist learning of DCS}

Virtual environment for training allows a constructivist perspective of learning: Learner will enhance his knowledge by being face to new situations. He will build his own representations [2]. DCS implie temporal or organisational constraints that make an automatic explanatory system hard to define. We will now introduce those situations

\subsection{Dynamic and collaborative situations}

Dynamic and collaborative situations can be found in various domains of teamwork with time pressure (rescue, security) [3] or in team sport [4].

This implies various protagonists that interact in a common environment and have to solve a problem. A collaboration between protagonists can be needed to solve the problem. Situation data can be interpreted according to the protagonists point of view and roles. Consequently, elements taken into account by a protagonist to take a decision are not easily predictable $[5,6]$.

We can exemplify those situations through an example of collective action in soccer. This action is illustrated by the figure 1 . A player $A l$ of the team $A$ has the ball. He is face to a player $B 1$ of the team $B$. There is a player $A 2$ of the team $A$ to the left of $B 1$. A collaboration can be possible between $A 1$ and $A 2$ to keep the ball and eliminate $B 1$.

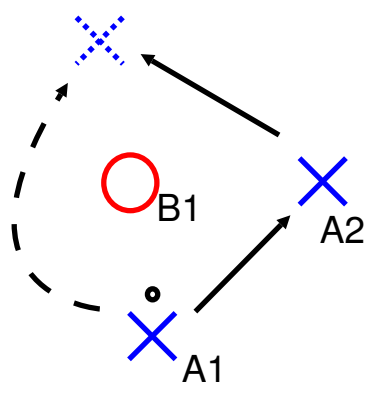

Figure 1. A simple dynamic and collaborative situation 


\subsection{Possible types of assistance}

For this purpose, we have identified two help types that can be set up. They are called on-line help and can be divided in two guidances:

- A guidance thanks to actions: that means a strong guidance. One shows a priori linkings that allows the sequence realisation. In order to do that, we introduce graphical elements which will represent actions that must be done before they appear. In the example given below, it is possible to add a ball going from the learner to his partner, or we can represent its trajectory with an arrow as it is shown on the figure 2 . This paper is focused on this help type.

- A guidance thanks to affordances: That means the learner will execute his action and if he makes a mistake, we can highlight some relevant elements he has missed. Those elements or affordances [7] must allow him to understand why he was mistaken. In our example, if he kept the ball, we could make his opponent bigger according to his distance. The closest he is, the biggest the opponent will be. Another solution consists in making his partner blinking. The crucial point is that the help is done only if the learner is mistaken.

Those two types can be made up thanks to contextual graphs. Now, we will explain what are those graphs that we are using to model our strategical contexts.

\section{Contextual graphs as learning support}

Our agent decision-making is based on the notion of context [8]. More precisely, we are using context-based reasoning (CxBR) that has been introduced in [9]. The definition and modelling of our context is based on psychologists point of view [10]. The modelling of our context have been described in [11]. This paper deals with contexts used for explanation, that are modelling thanks to contextual graphs [12] that we will introduce now:

\subsection{Context for explanation}

In our approach, a contextual graph represents actions sequence and relevant states to lead a collaboration until its end. Relevant states are characterized by objects or by particular attributes of objects. Those can be likened to the notion of affordances. Every state of the graph represents a context at a given instant of the collaboration and is called contextual node. The transition between two nodes can be done thanks to an action. The figure 3 shows a contextual graph, with contextual nodes and actions that we will describe now:

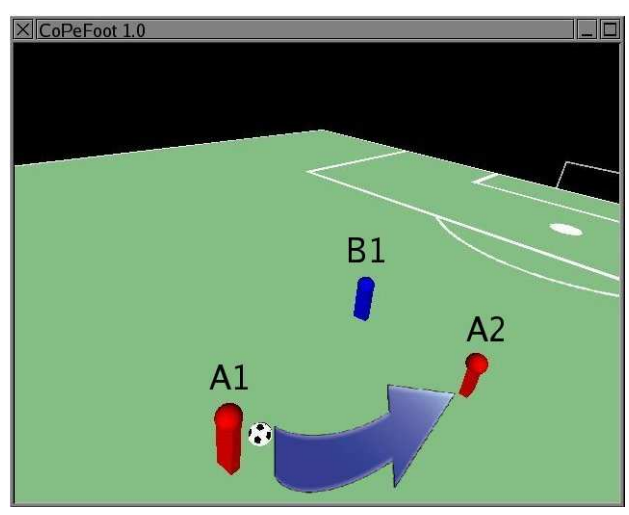

Figure 2. contextual help

\subsubsection{Actions}

Transitions in the graph represent actions that can be done according to the current context. They allow to highlight the link between two contextual nodes. They can be written thanks to a triplet that consists of an actor, the action and an object or a protagonist on which the action is performed. An action in a contextual graph looks like:

$A=<$ Actor, Action, Object $>$ where

- Actor: represents the player which performs the action

- Action: is the action, technically it is the name of the method which is called. Applied to soccer, an action can be pass, dribble or shakeOff...

- Object is an object or a protagonist on which the action is performed.

For example, $<P 1$,pass, $P 2>$ means that the player $P 1$ passes the ball to the player $P 2$. In the soccer example, an action is performed by the player which we are describing the context.

We will see later how this formalism of actions and contextual nodes allows to easily highlight relevant elements to set up pedagogical tool to help recognition of dynamic and collaborative situations. A triplet is used to represent an affordance too, as we will see in the next example.

\section{Example of contextual assistance}

We will now illustrate why and how our model allows to set up the pedagogical assistance. The trainer has first defined strategical context representing the situation that learner has to recognize. Every relevant actions and affordances are stored in the contextual graph. Each action and affordance can be linked to a graphical primitive for explanations. The strategical context looks like the graph of figure 3 . Where $b$ is the ball, $j$ the player, $p$ a partner, $o$ an opponent, $\operatorname{dist}(X)$ represents the distance to $X, \operatorname{position}(X)$ the 


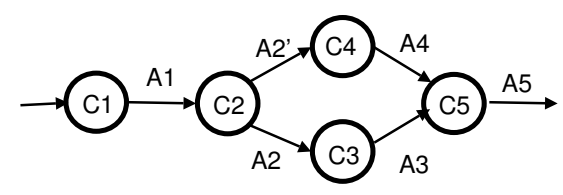

Figure 3. Strategical context of A1

position of $X$ that can have a value corresponding to a cardinal orientation. The next table presents relevant elements (affordances) of the first node and the action associated:

\begin{tabular}{|l|l|l|}
\hline Context & Description & Action \\
\hline $\mathrm{C} 1$ & $\mathrm{~b} \in \mathrm{j}$ & $\mathrm{A} 1=\{\mathrm{j}$, pass, $\mathrm{p}\}$ \\
& $\operatorname{dist}(\mathrm{o})<$ far & \\
& $\operatorname{position}(\mathrm{o})=\mathrm{N}$ & \\
& $\operatorname{dist}(\mathrm{p})<$ far & \\
& $\operatorname{position}(\mathrm{p})=\mathrm{NE}$ & \\
\hline
\end{tabular}

\subsection{Guidance before action}

A graphical primitive is associated with every action of the contextual graph. Thanks to this primitive, relevant action can be shown to the learner. We have already defined various graphical primitives like a dotted arrow used to represent a move. The distance between the learner and an object can be represented with a double arrow, that can illustrate if the object should be nearer or further.

The example given at the beginning of this article on the figure 2 shows an assistance that have been set up to highlight the relevant action. The current context is $C l$ of the strategical context of $A 1$. A curved arrow is drawn to represent the pass that the learner should do. To put in place, this graphical assistance, agent uses the triplet describing the action. Thanks to this it can determine the orientation and the position of the arrow.

\section{5 conclusion}

The aim of this article is to highlight the interest of using context in order to bring back relevant information to users (trainer or learner) in situations that can not be totally described by advance. We have described here the interest and the representation of our strategical context.

Using contextual graphs allows us to highlight relevant elements that correspond to the current situation according to the objectives. We have put in place two types of assistances, the guidance before action which is a strong guidance. The second type of guidance during action allows to bring to the fore elements that has not been taken into account.
We have focused our purpose on the guidance before action, but we could have done the same with the guidance during action. We are currently working on a third help type that allows to replay a situation.

\section{References}

[1] P. Fuchs, F. Nashashibi, and D. Lourdeaux. A theoretical approach of the design and evaluation of a virtual reality device.

[2] J. Piaget and B. Inhelder. The Psychology of the Child. NY: Basic Books, 1969.

[3] L. Rognin, P. Salembier, and M. Zouinar. Cooperation, interactions and socio-technical reliability: the case of air-traffic control. comparing french and irish settings. In Proceedings of the European Conference on Cognitive Ergonomics (ECCE9), 1998.

[4] M.T. Argilaga and G.K. Jonsson. Detection of realtime patterns in sports: Interactions in soccer. International Journal of Computer Science in Sport, Volume 2/Edition 2(1):118-121, 2003.

[5] David D. Woods. Coping with complexity: the psychology of human behaviour in complex systems. Tasks, errors, and mental models, pages 128-148, 1988.

[6] J-M Cellier and J-M Hoc. La gestion d'environnements dynamiques. Psychologie Francaise, 46:103-106, 2001.

[7] J. J. Gibson. The Ecological Approach to Visual Perception. Mifflin, Boston, 1979.

[8] R. M. Turner. Context-sensitive reasoning for autonomous agents and cooperative distributed problem solving, 1993.

[9] Avelino J. Gonzalez and Robert Ahlers. Contextbased representation of intelligent behavior in training simulations. Trans. Soc. Comput. Simul. Int., 15(4):153-166, 1998.

[10] B. Kokinov. A dynamic theory of implicit context, 1997.

[11] R. Bénard, C. Bossard, and P. De Loor. Context's modelling for participative simulation. In 19th International Florida Artificial Intelligence Research Society Conference (FLAIRS-06). AAAI, 2006.

[12] P. Brézillon. Context dynamic and explanation in contextual graphs. In Patrick Blackburn, Chiara Ghidini, Roy M. Turner, and Fausto Giunchiglia, editors, Modeling and Using Context: Fourth International and Interdisciplinary Conference, Context 2003, pages 94-106, Berlin, 2003. Springer-Verlag. 